\title{
A PLASTICIDADE DA NORMATIVIDADE: REFLEXÕES SOBRE A VIDA BIOLÓGICA E SOCIAL COM A DOENÇA DE CHAGAS
}

\author{
THE PLASTICITY OF NORMATIVITY: \\ SOME REFLECTIONS ON BIOLOGICAL AND \\ SOCIAL LIFE WITH CHAGAS DISEASE
}

\section{Kelly Koide ${ }^{1}$}

\begin{abstract}
Resumo: No presente artigo, elaboro uma reflexão acerca da ideia de individualidade orgânica na criação de normas e procuro compreender, por meio das obras do médico e filósofo francês Georges Canguilhem (1904-1995), em que sentido a patologia não poderia ser uma matéria esvaziada de subjetividade e, por esse motivo, não pode ser entendida apenas pela sua descrição anatomopatológica ou fisiológica. Para Canguilhem, definir a doença a partir de uma normalidade - esta última entendida como um padrão regular de atividade do organismo em condições definidas - leva a clínica a localizar a doença nos órgãos, nos tecidos, nas células e a partir dos prefixos "hiper", "hipo", "mega", que pressupõem um padrão normativo. Assim, a doença é identificada nas radiografias, ecografias, autópsias e nos laboratórios. Canguilhem defende, no entanto, que o patológico não pode ser classificado como um sintoma tomado isoladamente, pois ele só pode ser considerado enquanto tal em relação ao organismo em na sua totalidade. Nesse sentido, um fenômeno biológico não pode ser qualificado como patológico apenas por meio de um método objetivo. A reflexão aqui apresentada está ancorada em uma pesquisa de campo realizada em Recife, mais especificamente na experiência e na percepção de uma portadora da doença de Chagas, à luz de sua capacidade de criar novas normas de vida biológica e social.

Palavras-chave: normal; patológico; doença de Chagas; Georges Canguilhem
\end{abstract}

\begin{abstract}
This article aims to reflect on the idea of organic individuality on the creation of norms and to understand, through the works of the French physician and philosopher Georges Canguilhem (19041995), in what sense pathology cannot be a matter devoid of subjectivity and, therefore, cannot be understood only by its anatomopathological or physiological description. According to Canguilhem, by defining disease from normality - this term understood as a regular standard of organism's activity in established conditions - leads clinic to locate disease in the organs, tissues and cells, and from the prefixes "byper", "bypo", "mega", that presuppose a normative standard. Therefore, disease is identified in radiography, echocardiogram, autopsy and laboratory. Canguilhem argues, however, that the pathological cannot be classified as an isolated symptom, since it can only be considered as such in relation with the organism considered in its totality. In this sense. a biological phenomenon cannot be qualified as pathological only by using an objective method. The reflection presented here is based on a field research conducted in Recife (Brazil), more specifically on the experience and the perception of a person affected by Chagas disease, in the light of her ability to create new biological and social norms of life.
\end{abstract}

Keywords: normal; pathological; Chagas disease; Georges Canguilhem

\footnotetext{
${ }^{1}$ Pesquisadora da Associação Filosófica Scientiae Studia, do IEA/USP e do GRAVI/USP, onde participa de grupos de pesquisa e seminários. Orcid: http://orcid.org/0000-0003-0138-9815
} 


\section{INTRODUÇÃO}

A doença de Chagas é incurável. Não tardou para que as primeiras investigações sobre a tripanossomíase americana apontassem para esse diagnóstico. Tal adjetivo, frequentemente reiterado pelos médicos e pelas pessoas afetadas por esta enfermidade, constitui um ponto de partida para explorar algumas distinções importantes entre saúde e doença. Veremos, a partir das análises de Georges Canguilhem sobre essas distinções, em que sentido, nas manifestações associadas à tripanossomíase americana, "a pessoa é doente não apenas em relação aos outros, mas em relação a si mesma" (Canguilhem, 2009a, p. 53).

Tal concepção do doente possui duas premissas, que analisarei a seguir. A primeira delas é a progressiva dissociação entre a doença e o doente na medicina moderna, em que "os doentes são tratados não como sujeitos de sua doença, mas como objetos" (Canguilhem, 2002, p. 35). Para Canguilhem, essa dissociação expressa, em grande medida, uma tentativa de a medicina tornar a patologia objetiva, definindo o estado patológico como uma mera variação quantitativa do estado fisiológico (cf. 2009a, p. 33). Essa abordagem das doenças, distanciada do indivíduo doente, faz desaparecer toda a continuidade da experiência individual. No entanto, a patologia não pode ser uma "matéria desprovida de subjetividade" (2009a, p. 93); o organismo é o sujeito da doença, e o evento mesmo que representa a doença é produto de uma criação original desse organismo que modifica o devir da vida sem aboli-la.

Isso nos leva à segunda premissa. Se a pessoa é doente em relação a si mesma, isto é, a um estado anterior dela própria, isso significa que é a partir dos estados sucessivos de um mesmo indivíduo que a fronteira entre doença e saúde se apresenta. Assim, "a fronteira entre o normal e o patológico", afirma Canguilhem, "é imprecisa para diversos indivíduos considerados simultaneamente, mas é perfeitamente precisa para um único e mesmo indivíduo considerado sucessivamente" (Canguilhem, 2009a, p. 71). O sentido dessa afirmação reside em que a saúde designa não um estado, mas um limite das possibilidades de assumir riscos biológicos. Após a doença, novos limites individuais são fixados, devido à "plasticidade funcional do homem, ligada, nesse homem, à sua normatividade vital" (2009a, p. 68). ${ }^{2}$ Para Canguilhem, os indivíduos instituem suas normas biológicas, criando novas normas que tornem possível a afirmação da vida. A doença não é, portanto, a ausência de normas, mas uma redução da capacidade normativa do vivente.

Considerando, a partir das reflexões de Canguilhem, que as normas biológicas produzidas pelo vivente não são apenas sua submissão ao meio, mas também a instituição de seu próprio meio, então é no interior da relação que se institui entre ambos que os conceitos de normal e patológico podem ser definidos (cf. Canguilhem, 2009a, p. 92; Le Blanc, 2010b, p. 86). Nesse sentido, a experiência biológica e social de um indivíduo portador da doença de Chagas tem

\footnotetext{
2 O termo "homem" como significante universal para referir-se à espécie humana provém da junção de duas palavras em latim. De acordo com Patrizia Violi, “o próprio termo para designar a espécie humana é homem, segundo uma evolução que levou, por exemplo, nas línguas romanas, à supressão da oposição existente entre homo, genérico para a espécie, e vir, específico para os indivíduos do sexo masculino. Com a assimilação de uma só palavra, o masculino foi coincidir com o termo genérico da espécie, continuando, contudo, no plano semântico, a manter a ambiguidade de seu duplo nível de significação. Com efeito, a expressão não é um real genérico, mas um pseudo-genérico (ou genérico-específico) se, na percepção dos sujeitos falantes, não se associa à utilização do termo homem unicamente uma significação genérica como 'gênero humano', mas igualmente uma significação específica de 'indivíduo masculino'. Pensemos na incongruência semântica de frases como "o homem amamenta suas crianças"” (Violi, 1987, p. 31). Com essa nota, queremos apenas sinalizar que não faremos uso desse termo de maneira genérica no presente artigo, com exceção das citações textuais diretas.
}

PRACS: Revista Eletrônica de Humanidades do Curso de Ciências Sociais da UNIFAP https://periodicos.unifap.br/index.php/pracs ISSN 1984-4352 Macapá, v. 12, n. 1, p. 153-173, jan./jun. 2019 
em vista essa sucessão em relação a si mesmo no estabelecimento de novas formas de vida. Foi considerando a percepção do doente como ponto de partida para apreender a doença que analisarei a história de Joanda.

Em 2013, estabeleci contato com o Ambulatório de Doença de Chagas e Insuficiência Cardíaca / PROCAPE - UPE, conhecido como "Casa de Chagas", e coordenado pelo cardiologista Wilson de Oliveira Junior. No mês de novembro daquele ano, obtive a autorização do comitê de ética para realizar pesquisas de campo ali. O Ambulatório está localizado no bairro de Santo Amaro, no centro de Recife (Pernambuco) e, em uma casa contígua, está instalada a "Associação de Pacientes Portadores de Doença de Chagas e Insuficiência Cardíaca de Pernambuco". 3 Pouco depois de chegar ao Ambulatório, conheci Joanda enquanto voluntária da Associação e, posteriormente, como portadora da doença de Chagas.

Mas, antes de prosseguirmos, farei uma breve exposição sobre as circunstâncias históricas e o contexto social em que ocorre a tripanossomíase americana, para que o (a) leitor(a) possa compreender melhor em que consiste esta afecção.

\section{A DOENÇA DE CHAGAS}

O jovem médico Carlos Chagas viaja, em meados 1907, a Lassance, no norte de Minas Gerais, um dos municípios onde estava sendo construída uma estação da Estrada de Ferro Central do Brasil, ligando o Rio de Janeiro a Belém do Pará. Chagas foi incumbido por Oswaldo Cruz, então diretor-geral de Saúde Pública e diretor do Instituto Soroterápico Federal (que posteriormente veio a ser o Instituto Oswaldo Cruz), de combater uma epidemia de malária que assolava a região do rio das Velhas. Em meio às atividades de profilaxia de sua campanha anti-palúdica, Chagas não poderia suspeitar que justamente ali encontraria um problema científico de grande magnitude. Encontrando primeiramente um parasito e um vetor, identificou, pouco depois, uma nova patologia humana.

A sequência de eventos que culmina na solução de um complexo quebra-cabeça, e que constituem o ciclo da descoberta da doença, começa com a identificação de um parasito no sangue de saguis. Enquanto coordenava as atividades de profilaxia da malária, Chagas costumava examinar espécies da fauna brasileira. No vagão que lhe serve de laboratório e dormitório, ele examina, em 1908, o sangue de um sagui muito comum na região de Lassance, encontrando um protozoário. Este é identificado por Chagas como um tripanossoma, ${ }^{4}$ o qual nomeia Trypanosoma minasense; trata-se de um parasito habitual, não patogênico, do macaco (cf. Kropf, 2009, p. 95-7).

O segundo elemento dessa sequência é o reconhecimento de um inseto, o "barbeiro", sobre o qual Chagas formula a hipótese de ser o transmissor de algum parasita aos humanos ou aos animais. Chagas possuía conhecimentos em entomologia, sendo o seu interesse pelo assunto motivado, em grande medida, pela busca de insetos alados transmissores de doenças, em especial os mosquitos, entre os cientistas no início do século XX. Nesse período, recebem destaque as diversas pesquisas acerca do papel de insetos na transmissão de doenças, quando

\footnotetext{
${ }^{3}$ Essa associação realiza, desde 1987, um trabalho voluntário de atenção aos pacientes para promover sua autonomia em relação ao conhecimento e ao tratamento da doença, estando a Associação vinculada ao Ambulatório de Doença de Chagas e Insuficiência Cardíaca / PROCAPE - UPE.

${ }^{4}$ A classificação desses protozoários como pertencentes ao gênero Trypanosoma, cuja etimologia remete às palavras gregas trypanos (broca) e soma (corpo), deve-se ao fato de que esse parasita tem uma aparência espiralada, semelhante a um sacarolha (cf. Tortora et al., 2012, p. 4).
} 
teorias do modelo inseto-vetor são elaboradas e consolidadas no interior da medicina tropical. Inclusive, no mesmo ano em que Chagas ingressa na faculdade, em 1897, o britânico Ronald Ross demonstra que a transmissão da malária ocorre por intermédio do mosquito do gênero Culex (cf. França et al., 2008, p. 1273).

Chagas então faz uma viagem, juntamente com o médico Belisário Penna, a Pirapora, na qual dormem em um rancho às margens do riacho Buriti Pequeno com os engenheiros da ferrovia. Naquela cidade, o chefe da comissão de engenheiros, Cornélio Homem Cantarino Mota, mostra aos sanitaristas um inseto sugador de sangue muito comum na região, popularmente conhecido como "barbeiro". O inseto é assim denominado pela população pelo fato de frequentemente picar o rosto das pessoas enquanto elas dormem. Ademais, Chagas também menciona, como origem para aquele nome, o fato de ainda ser comum naquelas regiões os barbeiros-sangradores, importantes terapeutas populares da época, aplicarem sangrias com objetivos terapêuticos (cf. Chagas, 1910). O "barbeiro" era, então, um inseto hematófago muito comum naquela região de Minas e, segundo relata Chagas,

habita os domicílio humanos, atacando o homem à noite, depois de apagadas as luzes, ocultando-se, durante o dia, nas frestas das paredes, nas coberturas das casas, em todos os esconderijos, enfim, onde possa encontrar guarida. De regra, é o hematófago visto em maior abundância nas habitações pobres, nas choupanas de paredes não rebocadas e cobertas de capim. Ali, a reprodução dele é considerável; são encontrados em número imenso nas frestas das paredes e constituem condição anti-vital das mais notáveis, pela dificuldade trazida ao repouso do homem. Muitas vezes, verificamos o ataque do homem pelo hematófago: poucos minutos após a extinção da luz nos aposentos saem eles dos esconderijos, em grande número, e vêm picar os indivíduos, de preferência no rosto. Acendendo-se o lume, os hematófagos fogem rapidamente, sendo mesmo difícil, deste modo, a captura deles (Chagas, 2009 [1909], p. 159-60).

Devido ao interesse pela entomologia, Chagas já fazia alguns estudos sobre os mosquitos associados às campanhas sanitaristas contra a malária e a febre amarela das quais havia participado. Sabendo da importância de insetos hematófagos como transmissores de entidades parasitárias e causadores de patologias, Chagas passa a dissecar os "barbeiros". No intestino posterior desses insetos, encontra formas flageladas de um protozoário - terceiro elemento do quebra-cabeça -, o que o leva a elaborar duas hipóteses: poderia tratar-se de um parasito natural do inseto ou de uma fase do ciclo evolutivo de um tripanossoma em um vertebrado. Ele conjectura, além disso, que caso sua segunda hipótese se confirme, aquele parasito poderia ser o Trypanosoma minasense, e o "barbeiro" seria o inseto vetor que o transmite aos vertebrados dos quais se alimentava do sangue.

A constituição da tripanossomíase americana, ainda que assentada sobre diferentes disciplinas (protozoologia, entomologia, ecologia etc.), envolveu, para Delaporte, uma "hipótese extravagante" (Delaporte, 2003, p. 34). Afinal, relacionar um inseto domiciliado a um sagui selvagem para explicar o ciclo de transmissão parece, a princípio, ilógico. Pois, se os insetos habitam nos domicílios humanos e neles se reproduzem, como poderiam picar os saguis? Mas Chagas relaciona a forma evolutiva do tripanossoma que encontrou no sangue de saguis com aquelas outras encontradas no intestino dos "barbeiros", sendo necessário colocar à prova sua conjectura em animais não infectados (cf. Delaporte, 2003, p. 33-4).

Como não dispõe dos meios necessários para testar suas hipóteses, devido ao grande número de macacos infectados na região, Chagas envia a Manguinhos alguns exemplares 
daqueles insetos hematófagos, que possuem flagelados com características de critídias em seus intestinos. Solicita a Oswaldo Cruz que realize exames, a fim de esclarecer a plausibilidade de suas hipóteses. Cruz, por sua vez, realiza experimentos nos quais infecta macacos da espécie Callithrix penicillata, criados em laboratório, mediante a picada dos insetos que lhe haviam sido enviados (cf. Chagas, 2009 [1909], p. 160-1). Após cerca de um mês, Cruz encontra um grande número de tripanossomas no sangue dos macacos, que haviam adoecido.

Com essa confirmação, Chagas retorna ao Instituto em Manguinhos para analisar a quarta peça do problema. Observa, então, que aqueles protozoários possuem "morfologia inteiramente diversa da de qualquer das espécies conhecidas do gênero Trypanosoma” (Chagas, 2009 [1909], p. 160). Em homenagem a Oswaldo Cruz, Chagas nomeia o novo protozoário Trypanosoma cruzi.

Desde o momento em que Chagas estabelece o ciclo e as formas evolutivas do T. cruzi em humanos e nos insetos vetores, organiza-se um conjunto de evidências que constituem uma nova patologia humana. A especificidade desse novo objeto científico vai sendo delineada a partir da caracterização de três aspectos: o parasitológico, as formas clínicas e a epidemiologia.

Esses aspectos são explorados e construídos no interior de variadas disciplinas em diferentes momentos, produzindo sentidos em torno da doença de Chagas. Por meio da parasitologia, ela alcança um reconhecimento comparável ao de outras doenças tropicais, como a malária ${ }^{5}$ e a doença do sono. ${ }^{6}$ Já a entomologia associa-se à epidemiologia para dedicar-se ao estudo dos insetos vetores e infectados, permitindo elaborar mapas que mostravam a extensão do problema. A cardiologia, por sua vez, torna-se central para definir a tripanossomíase como uma doença crônica, de tal modo que ao eletrocardiograma será atribuído um importante valor no diagnóstico das alterações provocadas pelo parasita no miocárdio. Por fim, a partir dos anos 1960, a imunologia e a bioquímica deslocam o foco da doença para o desenvolvimento de métodos de diagnóstico, medicamentos e vacinas, estando o T. cru₹i no centro das pesquisas (cf. Coutinho, 1999; Zabala, 2010, p. 45).

Em meio à multiplicidade de aspectos científicos e médicos dessa patologia, a sua caracterização clínica também expressa a pluralidade de uma doença que não pode ser reduzida a apenas uma de suas manifestações. Uma das características peculiares da doença de Chagas é seu polimorfismo, já que ela possui uma fase aguda e outra crônica, com formas variadas. Durante a fase aguda, o quadro clínico varia conforme o local de entrada do parasito: através da pele,

\footnotetext{
${ }^{5}$ No período em que Chagas começa seus estudos na Faculdade de Medicina do Rio de Janeiro, em 1897, recebem destaque as diversas pesquisas acerca do papel de insetos na transmissão de doenças, em especial de doenças tropicais. Inclusive, no mesmo ano em que Chagas ingressa na faculdade, o britânico Ronald Ross demonstra que a transmissão da malária ocorre através do mosquito do gênero Culex (cf. França et al., 2008, p. 1273). Ross, um cirurgião do Indian Medical Service, estava realizando, desde 1894, investigações experimentais sobre a hipótese de Manson, de que os mosquitos relacionamse com a propagação da malária. E, em 1898, o ciclo dos mosquitos Culex, que transmitem malária às aves, é desvendado por Ross, de modo que ele estabelece o conceito de vetor. Inspirados por essa descoberta, o italiano Giovani Grassi e seus colaboradores estabelecem, no ano seguinte, que a malária humana é causada por um parasita transmitido por mosquitos do gênero Anopheles (cf. Benchimol, 1999, cap. 10; França et al., 2008, p. 1274).

${ }^{6}$ A tripanossomíase africana, conhecida como doença do sono, é uma doença "causada por um parasita protozoário hemoflagelado, o tripanossoma [Trypanosoma brucei gambiense]. Ela é transmitida através da picada da mosca tse-tsé, o vetor (...) Glossina palpalis" (Lyons, 2002, p. 42). A tripanossomíase africana é uma doença crônica, que age lentamente sobre o organismo, e ocorre na África Central e Ocidental. Entre 1901 e 1905, uma epidemia da doença do sono causa a morte de mais de 250.000 pessoas em Uganda, o que preocupa os países europeus que possuem colônias estabelecidas nas regiões afetadas da África - e que origina uma segregação racial e social permanente nas colônias africanas, na forma de medidas sanitárias (cf. Lyons, 2002, p. 37-40). Além disso, as tripanossomíases são atraentes para os pesquisadores por evocar questões referentes aos ciclos evolutivos dos protozoários (cf. Kropf, 2009, p. 96).
} 
pode haver inchaço e febre no local; se for pela conjuntiva ou pela área próxima aos olhos, há um característico edema palpebral unilateral (cf. Romaña, 2009 [1935]); em alguns casos, pode haver febre, inchaço das pernas, aumento do fígado e do baço, inchaço das glândulas linfáticas e inflamação do coração, com eventual parada cardíaca. Em crianças menores de dois anos, pessoas idosas, com imunodeficiência ou em indivíduos infectados com uma grande quantidade de parasitos (como no caso da ingestão de alimentos contaminados), a infecção pode ser mais severa e provocar a morte (cf. OMS, 2010, p. 77). Em seguida, os indivíduos entram em uma fase indeterminada (assintomática), a qual pode durar muitos anos ou mesmo toda a vida. Entre os que vêm a manifestar a doença na forma crônica, os indivíduos podem sofrer progressivos distúrbios e lesões cardíacas e digestivas (esôfago e cólon), o que causa também a dilatação devido à ação do parasito nos tecidos desses órgãos; em geral, as pessoas vêm a falecer em decorrência da insuficiência cardíaca (cf. OMS, 2010, p. 77).

\section{SENTIR-SE DOENTE}

O desconhecimento sobre a doença de Chagas não impediu que Joanda tivesse um marcapasso implantado em seu coração. ${ }^{7}$ Aos 12 anos, Joanda trabalhava em seu último emprego, em 1979, cuidando de crianças não muito mais jovens do que ela em Timbaúba, cidade onde nasceu, na Zona da Mata Norte de Pernambuco. Seus primeiros anos de vida foram marcados por um ambiente repleto de inseguranças e rejeições familiares, em parte devidas à precária situação socioeconômica dessa região. Ela relembra como foram seus primeiros anos de vida:

Minha infância em Timbaúba não foi boa, não. É até triste de contar. Eu não fui criada com a minha mãe. A minha mãe me deu para a mãe dela. A mãe dela não ficou comigo e teve umas histórias que o pessoal contou. Sei que fui crescer, ser criada com a mãe e o pai do meu pai. Mas eles já eram velhinhos e quem foi tomar conta de mim foi a minha tia. Do meu primeiro ano de vida até os meus 12 anos, nas minhas lembranças foi uma coisa meio turbulenta, confusa. Porque na idade que era pra brincar com boneca, estudar, eu fui trabalhar. Eu tomava conta de bebê.

Um dia, ela sentiu-se doente e foi levada a Recife, a cerca de 100 quilômetros de sua cidade natal, onde foi internada em um hospital. Pergunto a ela o que sentia quando estava "doente": "Eu desmaiava. Sei que depois de um desses desmaios, fui levada pra emergência do Hospital Oswaldo Cruz, porque não tinha o PROCAPE na época, e fiquei lá. ${ }^{8}$ Foi implantado o marcapasso, depois voltei pra minha cidade doente, né? Aí não tinha como trabalhar de novo porque ninguém queria uma pessoa com marca-passo".

A infecção de Joanda pelo T. cruzৃi ainda na infância não constitui um caso isolado na região. Recordemos a história da doença de Chagas. A dimensão epidemiológica da doença sempre

\footnotetext{
7 As percepções, experiências e conhecimentos de Joanda acerca da doença de Chagas foram por ela relatados em uma entrevista que realizei em novembro de 2013.

${ }^{8}$ O PROCAPE (Pronto-Socorro Cardiológico Universitário de Pernambuco Prof. Luiz Tavares), vinculado à Universidade de Pernambuco, é um hospital universitário, onde são realizados exames cardiológicos, tais como eletrocardiograma, testes ergométricos e holter - apenas para mencionar aqueles mais frequentemente mencionados por outros pacientes entrevistados. Nesse hospital público, que oferece atendimento por meio do Sistema Único de Saúde (SUS), também são realizadas intervenções cirúrgicas e exames sorológicos das pessoas que apresentam um quadro clínico que indica uma alta probabilidade de infecção pelo T. cruži, após realizarem uma consulta com os médicos da "Casa de Chagas". O espaço que sedia, atualmente, o Ambulatório encontra-se em frente ao PROCAPE, o que propicia a constante circulação de pacientes, voluntários, funcionários e médicos entre os dois locais.
}

PRACS: Revista Eletrônica de Humanidades do Curso de Ciências Sociais da UNIFAP https://periodicos.unifap.br/index.php/pracs ISSN 1984-4352 Macapá, v. 12, n. 1, p. 153-173, jan./jun. 2019 
foi apresentada como um critério de expressividade e de existência da doença em determinadas regiões. Nos lugares onde há um número considerável de casos da doença (na forma crônica ou aguda), em geral há fortes indícios da transmissão vetorial da doença; e, com poucas exceções, ela está relacionada a certas condições sociais engendradas pela exploração da força de trabalho.

Em uma investigação clínica e epidemiológica no estado de Pernambuco, alguns anos antes do nascimento de Joanda, Ruy João Marques realizou, em 1955, um levantamento epidemiológico dos casos de infecção pelo T. cruzi.$^{9}$ Percorrendo vinte municípios das diferentes zonas do estado, parte da investigação de Marques consistiu em estimar a incidência de espécies transmissoras e os respectivos índices de infecção (cf. Marques, 1955, p. 37-53). Marques e sua equipe analisaram 5141 casas, onde foram recolhidos 3558 triatomíneos; destes, 11,99\% estavam infectados com o parasita. É interessante notar que Marques também afirma que, em suas investigações,

predominaram os trabalhadores rurais, mas vale salientar que em qualquer profissão, desde que se esteja ou tenha estado em zona endêmica dormindo em casa infestada, as probabilidades de adquirir a moléstia são as mesmas (Marques, 1955, p. 116).

O caráter pungente dessa afirmação reside no fato de que a Zona da Mata pernambucana, onde Timbaúba está situada, é uma área historicamente marcada pela plantação de cana-deaçúcar em Pernambuco. Já na primeira metade do século XVI, foram construídos os primeiros engenhos coloniais em Pernambuco, baseados na exploração da mão de obra escravizada. As atividades agrárias implementadas pelos portugueses no Brasil colonial foram feitas de maneira devastadora, iniciando-se ciclos de plantios em novas áreas a cada vez que se esgotavam os recursos naturais. Além disso, a fixação ao solo dos trabalhadores escravizados, que deveriam ficar próximos às plantações de cana e aos engenhos, tornou-se possível por meio da construção de casas de taipa, favorecendo a infestação domiciliar de triatomíneos (cf. Ribeiro, 1995; Prado Jr., 2011).

Caio Prado Jr. ressalta que a manutenção da "massa da população brasileira naquele grau ínfimo de existência material" não se dava apenas por meio da escravidão, mas da própria organização econômica e social do país, baseada na monocultura, na grande propriedade e no trabalho escravo (2011, p. 129). A Abolição não significou senão a mudança de "estatuto jurídico e nominal do trabalhador", considerando-se que a escravidão era apenas um dos aspectos dessa organização que originou e manteve a concentração de riquezas e, consequentemente, a presença de indivíduos desprovidos de bens (Prado Jr., 2011, p. 129, nota 4).

Portanto, as condições sociais e materiais que constituíram um meio propício para que Joanda fosse picada por um "barbeiro" estavam presentes desde a construção dos primeiros engenhos, e perduraram ao longo do século XX. Além de ter nascido em uma região endêmica da doença de Chagas, Joanda - como a maior parte das pessoas que foram infectadas pelo $T$. cruæi no Brasil - morou em uma dessas habitações, típicas de trabalhadores rurais, como ela relata: "Onde eu morei, não era nem casa de taipa, era de palha. Palha e barro. Aí onde eles [os "barbeiros"] moravam era ali, naquelas frestinhas. Tem a [casa de] taipa, que é feita de pau e barro. Já a casa do meu pai, era mais fraquinha ainda”.

9 Trata-se da tese de Marques para ocupar a cadeira de Clínica de Doenças Infecciosas e Parasitárias da Faculdade de Medicina da Universidade Federal de Pernambuco, intitulada Alguns aspectos da doença de Chagas em Pernambuco (1955). 
Sendo o tipo predominante de habitação rural em diversas regiões do Brasil, as casas de barro e palha foram identificadas como o principal meio de contato entre pessoas e triatomíneos. Conforme mencionado por Joanda, as diversas fissuras e fendas nas paredes permitem que os triatomíneos se domiciliem, se reproduzam e infectem pessoas e animais mantidos próximos às casas, criando um ciclo doméstico e peridoméstico. Uma vez que a doença de Chagas é transmitida por um inseto, as condições sociais e ecológicas que permitem o contato permanente entre os "barbeiros" e diversas populações precisam ser analisadas sob um ponto de vista epidemiológico, já que nem todos os ambientes são propícios para que a infecção pelo T. cruzi ocorra. No caso dessa doença, portanto, o meio determinou e condicionou o surgimento e a distribuição social da doença.

Mas retornemos ao momento da história de Joanda em que ela sentiu-se doente. Como mencionou no início, ela havia enfrentado dificuldades para encontrar uma atividade remunerada após a cirurgia de implantação do marca-passo. Não é difícil imaginar as dificuldades sociais e econômicas nesse contexto rural em Pernambuco. Devido ao preconceito gerado por ser portadora de um marca-passo, que dificultou seu acesso ao mercado de trabalho formal e informal, Joanda não conseguia mais contribuir com a renda da família. Em meio a uma nova rejeição familiar, ela relata o que se seguiu à sua cirurgia:

Apareceu um rapaz e falou: "vou levar você para te criar". Aí o que foi que eu fiz? Fui com ele. Aí não quis saber, que a família já não ligava pra mim. Vou lhe confessar: não importava pra mim se eu tivesse uma doença que eu fosse morrer. Pra mim, não era nada. Porque pra mim, era a mesma coisa ter uma doença que eu fosse morrer hoje ou amanhã, não ligava muito, não. Porque eu era maltratada pelo marido, pela mãe dele, por toda a família". Perguntei-lhe se o marido era o homem que a havia adotado: "Foi. Mas ele me deixou. Não me deixou, não: me abandonou. Eu tava grávida de 6 meses, ele arrumou outra mulher e foi embora. Eu fiquei com a mãe dele, morei com ela.

Após a implantação do marca-passo, Joanda experimentou um sentimento de impotência e sofrimento que se intensificava naquele meio social. Assim, sua doença estava envolta de um sentido social, não sendo apenas uma alteração em seu organismo. Parece-nos que esse sentimento pode ser interpretado através da distinção entre doença (disease) e padecimento (illness) presente na antropologia da medicina (cf. Mol, 2002; e também Alves \& Rabelo, 1998). Annemarie Mol concebe a doença como um estado de um corpo físico e, enquanto tal, é um objeto de interesse da biomedicina. No entanto, a doença tem, segundo Mol, um significado para os pacientes, associados a sentimentos e interpretações elaboradas por eles, mas que também possuem especificidades históricas e culturais. Assim, o padecimento designa "a interpretação de um paciente de sua doença, dos sentimentos que a acompanham, os eventos da vida que ela traz" (Mol, 2002, p. 9). Ao fazer essa distinção, a autora salienta a existência de duas perspectivas sobre a doença, considerando ambas como interpretações desta: enquanto os médicos interpretam os corpos e as vidas de outrem, os pacientes o fazem a partir de sua própria experiência. Nesse sentido, Mol coloca a perspectiva de médicos e pacientes no mesmo nível epistêmico; a distinção entre doença e padecimento não é feita para contrastar estados físicos e significados pessoais, mas apenas para diferenciar as perspectivas de ambos (cf. Mol, 2002, p. 10-1).

Mol desdobra essa distinção entre doença e padecimento para explorar questões que não 
tratarei aqui, ${ }^{10}$ mas acredito que ela pode dialogar com os conceitos de normal e patológico, e dos valores individuais de que trata Canguilhem. O sentido dessa afirmação que pretendo explorar é o seguinte. Se a afecção cardíaca que Joanda porta pode ser considerada uma patologia, é apenas na relação entre o organismo e seu meio que ela pode ser compreendida enquanto tal. Assim, essa variação biológica deve ser colocada em relação à experiência subjetiva e, no caso de engendrar no indivíduo um sentimento de sofrimento e impotência, então se trata de uma anormalidade (cf. Canguilhem, 2009a, p. 53). Essa anormalidade só pode ser concebida a partir da perspectiva de Joanda (enquanto "padecimento"), e não por uma atribuição de um médico a um estado físico correspondente (enquanto "doença”, nos termos de Mol).

Tal maneira de conceber a patologia nos parece relevante nesse ponto específico da história de Joanda na medida em que, ainda que o marca-passo implantado alterasse uma constante fisiológica (pulsação cardíaca), sua doença era definida a partir de seu próprio julgamento e de seu meio social. Para Canguilhem,

é a apreciação dos pacientes e das ideias dominantes do meio social que determina o que se chama "doença" (...). Estar doente significa ser nocivo ou indesejável ou socialmente desvalorizado (Canguilhem, 2009a, p. 46).

Assim, a doença surge como experiência reveladora de uma história humana da vida, que a modifica, reduzindo a capacidade do indivíduo de modificar a si mesmo. A doença diminui as possibilidades de criar novas possibilidades e, nesse sentido, Canguilhem faz uma passagem da individualidade biológica à subjetividade, já que é o indivíduo que dá sentido subjetivamente à sua doença. É, portanto, o indivíduo que se sente doente e, por meio da doença e da diminuição qualitativa que ela engendra, a subjetividade é modificada pela patologia (cf. Le Blanc, 2010b, p. 114-5). Vejamos como Canguilhem situa o vivente no interior de sua análise do normal e do patológico, fazendo a passagem do vivente animal para o vivente humano, da individualidade biológica para a subjetividade no interior desta.

Ao conceber a doença em termos de valorização na relação com o meio, abre-se a possibilidade de analisar a interpretação da doença por meio da percepção do indivíduo. Assim, a aproximação entre a epistemologia de Canguilhem e o relato de Joanda possibilita analisar a doença de Chagas sob a percepção individual da patologia; não apenas em termos de limitações de seu poder físico, mas também como um processo de adoecimento baseado em sua história individual (cf. Canguilhem, 2002, p. 89). Afinal, é apenas nessa história, e não nas alterações dos órgãos e dos tecidos parasitados, que o sofrimento pode ser entendido no interior de um processo de valorização. Dito de outra maneira, é possível afirmar que Joanda estava doente na medida em que, em sua experiência, ela sentiu uma redução qualitativa em sua interação com o meio? Para respondermos a essa questão, é preciso situá-la no contexto da crítica à medicina em que se insere.

No Ensaio sobre alguns problemas relativos ao normal e ao patológico, tese defendida por Canguilhem em 1943, surge a crítica ao projeto de uma medicina fundada sobre representações científicas. Já no início da introdução do Ensaio, Canguilhem explicita que o problema a ser tratado será

${ }^{10}$ Nessa obra em particular, The body multiple (2002), Mol defende que as doenças surgem e desaparecem com as práticas nas quais são manipuladas. Como as doenças diferem de uma prática para outra, a doença se multiplica em diferentes realidades. Nesse sentido, a realidade é parte das várias práticas e é por elas criadas e sustentadas. O corpo, o paciente, o médico, o técnico, a tecnologia manipulam a doença em práticas diferentes, de modo que a doença é ontologicamente múltipla. 
o "das estruturas e dos comportamentos patológicos no homem" (2009a, p. 10). Esse problema é enfrentado por meio de duas abordagens diferentes nas duas partes em que a obra está dividida.

$\mathrm{Na}$ primeira parte, o autor faz uma análise da tese, historicamente situada no século XIX, segundo a qual "os fenômenos patológicos são idênticos aos fenômenos normais correspondentes, salvo pelas variações quantitativas” (2009a, p. 11). Já na segunda parte, procura mostrar a originalidade do conceito de norma, argumentando que o estado patológico é normal em relação à polaridade dinâmica da vida. Vinte anos mais tarde, Canguilhem escreveu três textos, ${ }^{11}$ os quais foram incluídos, sob a forma de um novo capítulo, na publicação do livro $O$ normal e o patológico (2009a), em 1966.

Essas reflexões sobre normalidade e patologia - centrais na obra de Canguilhem e de muitos de seus comentadores - nos permitem colocar a incurabilidade da tripanossomíase americana no plano da polaridade dinâmica da vida. Pensando na cura não como retorno a um estado anterior, mas como a criação de novas normas de vida (cf. Canguilhem, 2009a, p. 92), tentaremos compreender o horizonte em que a doença de Chagas pode ser considerada uma normatividade vital para Joanda.

\section{SAÚDE E DOENÇA: UMA FRONTEIRA}

Canguilhem apresenta uma epistemologia centrada no vivente, na qual a diferença entre saúde e doença emerge como uma alteração qualitativa na experiência individual. Essa diferença qualitativa, que consiste em uma "redução da margem de tolerância às infidelidades do meio” (2009a, p. 78), delimita, então, a fronteira onde começa a doença. É na percepção do indivíduo, em sua atividade normativa, portanto, que tal fronteira pode tornar-se palpável. Essa atividade normativa, que envolve uma luta do vivente contra aquilo que constitui um obstáculo à sua manutenção e ao seu desenvolvimento, esforçando-se para permanecer vivo, se dá na interação com o meio. Contudo, se Canguilhem fala em infidelidades do meio, não pretende, com isso, conceber a interação entre o vivente e o meio como uma mera submissão do primeiro ao segundo:

como vivente, o homem não escapa da lei geral dos viventes. O meio próprio do homem é o mundo de sua percepção, ou seja, o campo de sua experiência pragmática no qual suas ações, orientadas e reguladas pelos valores imanentes às tendências, recortam objetos qualificados, situam-nos uns em relação aos outros e todos em relação a ele. De modo que o ambiente ao qual ele supostamente reage encontra-se originalmente centrado nele e por ele (2009b, p. 195).

\footnotetext{
11 O conjunto desses artigos foi agrupado sob o título "Novas reflexões referentes ao normal e ao patológico (1963-1966)". Elisabeth Roudinesco afirma que, ainda que Canguilhem tenha realizado diversas modificações em relação à obra original, "a modificação essencial, a de 1966, explicava-se pela leitura que Canguilhem fizera do livro de Michel Foucault, $O$ nascimento da clínica (2006) [1963]" (Roudinesco, 2007, p. 44). Canguilhem foi professor de Foucault, tendo orientado sua tese de filosofia, Loucura e desrazão: história da loucura na idade clássica. Ao analisar a maneira como a psiquiatria pensava a loucura, Foucault propôs uma concepção de norma enquanto construção histórica ligada à ordem social. Nesse sentido, "opunha uma normatividade social à normatividade biológica [canguilhemiana]" (2007, p. 45), instigando Canguilhem a repensar sua própria noção de norma, atribuindo-lhe um status paradoxal, em que a patologia tem prioridade sobre a normalidade.
} 
Se a vida é a instituição de seu próprio meio, o vivente institui normas relativas à apreciação valorativa dos fatos que lhe permitem lutar contra aquilo que constitui um obstáculo à sua manutenção e ao seu desenvolvimento. É nesse sentido que Canguilhem afirma que a "vida não é indiferente às condições nas quais ela é possível, que a vida é polaridade e, por isso mesmo, posição inconsciente de valor, em resumo, que a vida é, de fato, uma atividade normativa" (2009a, p. 48).

De acordo com Guillaume Le Blanc, norma e valor possuem um sentido equivalente para Canguilhem, na medida em que "a norma é o que refere um fato a um valor (...). Uma norma biológica é a inscrição na vida de um valor imanente à vida” (Le Blanc 2010a, p. 33, nota 1). Notemos que é sob essa perspectiva que Canguilhem considera que a vida não é indiferente às condições nas quais ela é possível: ao buscar as condições para manter sua saúde, o organismo simultaneamente afasta os perigos que ameaçam essa manutenção, instituindo valores no meio e em si próprio. A polaridade da vida surge, então, devido ao duplo valor da normatividade.

Afirmando, por um lado, uma sustentação para o desenvolvimento da vida, em um esforço para melhorá-la e mantê-la e, por outro, reagindo aos obstáculos à sua manutenção e ao seu desenvolvimento, o vivente produz suas normas ou valores biológicos. Esta é a posição de valor em relação à polaridade da vida, que constitui uma normatividade, à qual se refere Canguilhem. Estando exposto aos riscos e eventuais perigos que o meio apresenta, o vivente valoriza certas condições que lhe possibilitam a manutenção da vida e apreende, sob a forma de valores negativos, os estados e comportamentos que perturbam ou são nocivos em relação ao meio (cf. Canguilhem, 2009a, p. 48). É nesse sentido que Canguilhem afirma que "a vida é essa atividade polarizada de conflito com o meio, e que se sente ou não normal, conforme se sinta ou não em posição normativa" (2009a, p. 91).

É nessa polaridade da vida em relação ao meio que a saúde e a doença podem se apresentar ao indivíduo. A vida mantém uma luta permanente de coesão e desenvolvimento contra os riscos que se lhe apresentam como possibilidade de destruição. Nesse esforço para permanecer em vida, o vivente desenvolve seus valores biológicos de regulação e produção, que lhe asseguram uma coerência interna. Assim, se Canguilhem afirma que "a vida procura ganhar da morte" (2009a, p. 107), é no sentido de que a possibilidade de destruição suscita o esforço do vivente para desenvolver-se. Dito de outra maneira, são os valores negativos (a dor, a morte, as dificuldades, a doença, a angústia) que fazem surgir uma valorização da vida, que transformam a vida em valor. A polaridade dinâmica da vida surge, portanto, de seu conflito com a morte, do risco permanente que a morte apresenta ao vivente.

Ao produzir seus valores biológicos, o vivente expressa uma atividade fundamental da vida contra aquilo que o ameaça. A normatividade é, portanto, posição de valor, pois o vivente exprime uma posição individual em relação ao meio. Ela é também a chave para compreender a fronteira entre o normal e o patológico: para um organismo, a normalidade vem de sua normatividade. Assim, a norma é a sua capacidade de criar novas normas, de modo que "o homem normal é o homem normativo, o ser capaz de instituir novas normas, mesmo orgânicas" (2009a, p. 54). Essa invenção de novas normas ou a possibilidade de fazê-lo é o que define a saúde enquanto atividade normativa.

O que caracteriza a saúde é a possibilidade de ultrapassar a norma que define o normal momentâneo, a possibilidade de tolerar infrações à norma habitual e de instituir normas novas em 
situações novas (Canguilhem, 2009a, p. 77).

Definindo a saúde em termos da capacidade do indivíduo de criar novas normas, ela passa a indicar a possibilidade de correr riscos frente ao imprevisto, de superar a norma que define o normal de outrora. Assim, a saúde é, como já mencionado, uma margem de tolerância às infidelidades do meio, indicando um limite para o vivente. Limite esse que o vivente sempre poderá ultrapassar, superando a capacidade presumida de reagir às mudanças do ambiente, em um mundo de acidentes possíveis (cf. 2009a, p. 78). Nesse sentido, a saúde é um "luxo biológico": é poder comer em horários inusitados, poder voltar para casa a pé se o último trem já tiver passado, em suma, é a possibilidade de enfrentar os riscos conduzindo a vida a possibilidades inexploradas, a possibilidades normativas (cf. 2009a, p. 78). A saúde se dá, portanto, na relação entre o vivente e o meio, mas não apenas em termos de adaptação e conformação passiva ao seu entorno. Afinal, para Canguilhem, a normatividade é inventiva, permitindo ao indivíduo criar o meio à medida que se adapta a ele, delimitando o meio e estruturando o seu próprio campo de experiência:

nesse sentido, o organismo não está jogado em um meio ao qual ele tem de se dobrar, mas, ao contrário, ele estrutura seu meio ao mesmo tempo que desenvolve suas capacidades de organismo (2009a, p. 130).

Se a saúde pode ser caracterizada como uma plasticidade individual diante das infidelidades do meio, o que significa a adaptação completa ao meio, isto é, uma fidelidade a certas normas de vida? Ora, considerando a saúde como a possibilidade do vivente de transgredir seus próprios limites, então a restrição desses limites é o que caracteriza a doença. A adaptação ao meio representa uma diminuição das possibilidades de criar novas normas e de suportar as mudanças e infidelidades do meio. A doença impõe os limites do possível, o que leva Canguilhem a afirmar que

o homem normal é o homem normativo, o ser capaz de instituir novas normas, mesmo orgânicas. Uma norma única de vida é sentida de modo privativo, e não positivamente (2009a, p. 54).

Se a saúde é a plasticidade do vivente para instituir sempre novas normas, a adaptação excessiva coloca a vida, que é uma atividade criadora, em perigo. Afinal, a saúde não é uma ordem perfeita, uma espécie de inocência orgânica definitiva, mas um esforço permanente de busca de equilíbrio, de restabelecer ou reforçar uma organização dinâmica. A doença designa, para Canguilhem, "o risco do vivente enquanto tal, risco tanto para o animal quanto para o vegetal ou o homem” (2002, p. 35). Lembremos que, para o autor, a vida é polaridade, e o vivente apreende, sob a forma de valores negativos, os estados e os comportamentos que constituem um obstáculo à sua manutenção e ao seu desenvolvimento, assim como os riscos que ameaçam a vida.

São esses riscos, no entanto, que conduzem o vivente à criação de novas normas, a explorar novas possibilidades desconhecidas. Assim, "a doença é um risco vital para a tomada de risco que é a vida” (Le Blanc, 2010a, p. 75). A doença não é a ausência de normas, mas a produção de outras diante dos riscos que constantemente ameaçam a vida. Trata-se de uma normalidade restrita enquanto a criação de um novo arranjo: "o patológico não é a ausência de norma biológica, é uma norma diferente, mas comparativamente repelida pela vida" (Canguilhem, 
2009a, p. 56).

Essa norma diferente é sentida pelo indivíduo considerado sucessivamente e "o indivíduo é que avalia essa transformação", nos diz Canguilhem, "porque é ele que sofre com as consequências, no próprio momento em que se sente incapaz de realizar as novas tarefas que a nova situação lhe impõe." (2009a, p. 71).

Para Joanda, as normas restritas, isto é, a fronteira entre a saúde e a doença se apresentavam de maneira clara. Quando perguntei como ela sentia a doença atualmente, Joanda afirmou que sentia cansaço para realizar tarefas que antes não lhe exigiam um esforço considerável:

É assim: vou lavar a louça. Aí quando estou na metade da panela, não tenho mais força de arear a panela, ou se eu for varrer a casa, de terminar de varrer. Fico cansada. Eu tenho o meu limite. Eu varro o quarto, aí me sento, faço uma coisinha. Como agora, por exemplo: fui pro PROCAPE acompanhar um paciente que foi fazer exames, mas graças a Deus, Jesus é tão bom que mandou a senhora pra conversar comigo. Pode olhar que eu vou avexadinha, que parece que o mundo vai se acabar. E eu pedindo a Deus que mande alguém junto de mim pra eu respirar uma coisinha.

Nas tarefas cotidianas, como lavar a louça, varrer o chão ou andar rápido, Joanda sentia seus limites restritos. Se ela sente cansaço, é em relação a um estado anterior no qual não o sentia, e é nesse sentido que não há indiferença biológica na concretude da vida. Mas, pelo fato de a doença de Chagas ser crônica e degenerativa, seria possível talvez concluir que o desequilíbrio do organismo de Joanda é permanente, expressando a ausência de normas biológicas. Ora, para Canguilhem, a estabilidade do organismo se encontra na regularidade de seu funcionamento. Mas essa regularidade não encontra uma forma única; ela constitui um leque de possibilidades qualitativamente diferentes que permitem que esse organismo se adapte. Assim, o organismo doente não é anormal, pois apesar da anormalidade que ele sofre, ele vive. Nesse sentido, o organismo negocia um novo "equilíbrio instável de normas” (2009a, p. 63), isto é, uma nova normalidade.

Nesse ponto, é importante ressaltar que Canguilhem não relativiza as distinções entre saúde e doença, entre o normal e o patológico. A chave para compreender tal distinção está na diferença qualitativa entre ambos que, como mencionei anteriormente, Canguilhem afirma ser possível determinar para um único e mesmo indivíduo, mas não pode sê-lo de forma clara para vários indivíduos comparativamente. Para compreendermos a insistência do autor sobre as diferenças qualitativas entre o normal e o patológico, vejamos por que a recusa de Canguilhem a atribuir às variações quantitativas a distinção entre saúde e doença.

\section{QUANTIDADE E QUALIDADE}

A doença, que define-se sempre a partir de seu binômio oposto, a saúde, foi tratada por Canguilhem em uma interessante discussão acerca da equivocidade do termo "normal", partindo do Vocabulaire technique et critique de la philosophie de Lalande (cf. Canguilhem, 2009a, p. 48). Por meio de um exame etimológico do termo, normal é "aquilo que não se inclina nem para a esquerda nem para a direita, portanto o que se conserva num justo meio termo", pois "norma" significa "esquadro". Daí, Canguilhem nos diz que derivam dois sentidos de normal:

é normal aquilo que é como deve ser; e é normal, no sentido mais usual da palavra, o que se 
encontra na maior parte dos casos de uma espécie determinada ou o que constitui a média ou o módulo de uma característica mensurável (2009a, p. 48).

Ora, Canguilhem nos afirma que a equivocidade desses sentidos provém justamente do fato de que o termo designa, ao mesmo tempo, um fato e um valor. O normal seria, portanto, um fato enquanto generalidade observável por meio de uma média estatística ou de uma variação quantitativa de funções fisiológicas. Disso decorre que "uma generalidade observável adquire o caráter de um valor: o valor de tipo ideal” (2009a, p. 48; grifos nossos). Nesse registro, haveria uma continuidade entre o normal e o patológico, onde este último seria um "subvalor destinado a esclarecer o valor da saúde" (Le Blanc, 2010a, p. 32). Considerada como uma mera variação quantitativa, a experiência individual da distinção entre saúde e doença foi sendo anulada na clínica.

Ao recusar essa homogeneidade entre o normal e o patológico, Canguilhem o faz enquanto crítica ao dogma positivista da doença que, segundo o autor, foi difundido por meio das teorias de Auguste Comte (1798-1857) e Claude Bernard (1813-1878), cujas origens podem ser encontradas no primado da fisiologia sobre a patologia, isto é, na concepção de que os fenômenos patológicos são apenas variações dos fenômenos fisiológicos correspondentes (2009a, p. 14). Tal concepção se inseriu, na interpretação de Canguilhem, em um projeto de tornar a terapêutica integralmente científica, algo que só seria possível se fosse possível "traduzir qualquer diferença entre o estado normal e o estado patológico em termos de quantidade" (2009a, p. 20). Assim, a patologia tornar-se-ia, ela também, científica, na medida em que fosse possível elaborar uma definição objetiva do normal (cf. 2009a, p. 20).

Se Canguilhem vê nesses dois autores o surgimento de uma concepção da doença "não mais pensada como uma experiência vivida, engendrando transtornos e desordens, mas como uma experimentação aumentando as leis do normal” (Le Blanc, 2010a, p. 34), ele identifica objetivos diferentes nos dois autores. Enquanto Comte busca uma identidade conceitual do normal, Bernard irá interpretar essa identidade em termos quantitativos e mensuráveis. Assim, sobre Comte, nos dirá Canguilhem que

o interesse se dirige do patológico para o normal, com a finalidade de determinar especulativamente as leis do normal, pois é como substituto de uma experimentação biológica muitas vezes impraticável - sobretudo no homem - que a doença aparece como digna de estudos sistemáticos. A identidade do normal e do patológico é afirmada em proveito do conhecimento do normal (Canguilhem, 2009a, p. 14).

A doença teria um papel, portanto, de experimentação espontânea, permitindo revelar o normal sem modificar seus traços e, assim, determinar as leis do normal. Nesse sentido, o "fenômeno patológico tem sempre seu análogo em um fenômeno fisiológico, não constituindo nada de radicalmente novo" (Canguilhem, 2009a, p. 18). Comte concebe a doença não enquanto uma força criadora, mas apenas como uma mera variação do normal, uma vez que saúde e doença são fenômenos regidos pelas mesmas normas. No entanto, ele não fornece exemplos para essas proposições gerais, tampouco apresenta qualquer "critério que permita reconhecer a normalidade de um fenômeno" (2009a, p. 18), o que leva Canguilhem a afirmar que, nessa perspectiva, o normal permanece como uma mera abstração, sem designar qualquer experiência vivida da doença.

Claude Bernard, por sua vez, concebe "a medicina como uma ciência das doenças, e a 
fisiologia como a ciência da vida" (Canguilhem, 2009a, p. 25). Considerando que o principal problema da medicina consiste em conservar a saúde e curar as doenças, Bernard defende que a terapêutica deve se assentar sobre uma ciência fisiológica. Os fenômenos fisiológicos devem ser conhecidos em seus aspectos físicos e químicos e, então, fornecerão as condições de avaliar as perturbações que podem sofrer no estado patológico. Este último consiste em uma variação quantitativa do estado normal, o que explica por quê, para Bernard, a "terapêutica racional só poderia ser sustentada por uma patologia científica e uma patologia científica deve se basear na ciência fisiológica" (2009a, p. 25).

Nesse sentido, o normal é fruto de medições, as quais podem ser experimentalmente estabelecidas. Por isso, Canguilhem afirma que Bernard "traz, para sustentar seu princípio geral de patologia, argumentos controláveis, protocolos de experiências, e sobretudo métodos de quantificação dos conceitos fisiológicos" (2009a, p. 28). A doença é explicada, portanto, em termos de mecanismos anatomo-fisiológicos, enquanto variações mensuráveis de um fenômeno homogêneo. Enquanto uma "patologia atomística" (2009b, p. 213), que divide o organismo e impede de considerá-lo uma totalidade viva, a doença é localizada em variações quantitativas de fenômenos fisiológicos precisos.

Uma das consequências da identificação entre o normal e o patológico é, segundo Canguilhem, o primado da fisiologia sobre a terapêutica, na medida em que se concebe o patológico como uma realidade provisória em relação ao normal. Nesse sentido, a terapêutica tem como objetivo instaurar e restaurar os fenômenos fisiológicos normais cientificamente estabelecidos.

Canguilhem não aceita essa noção da doença como variações quantitativas do normal porque recusa justamente a homogeneidade entre saúde e doença. Pois tal concepção supõe um tipo ideal, que seria a saúde perfeita, da qual a patologia nada mais é do que um desvio em relação à norma. A mensuração e quantificação da norma faz surgir, desse modo, um normal científico que substitui o normal vivente, "de tal sorte que a atividade normativa da vida, reprimida pela atividade normativa da ciência, não pode mais aparecer senão como um conceito secundário redutível a uma abordagem objetivamente determinável por métodos científicos" (Le Blanc, 2010a, p. 62).

No entanto, a norma não existe, nos dirá Canguilhem, não tendo qualquer sentido absoluto ou essencial, uma vez que nem o vivente nem o meio podem ser ditos normais enquanto tais, mas apenas em relação:

uma norma não existe, apenas desempenha seu papel que é de desvalorizar a existência para permitir a correção dessa mesma existência. Dizer que a saúde perfeita não existe é apenas dizer que o conceito de saúde não é o de uma existência, mas sim o de uma norma cuja função e cujo valor é relacionar essa norma com a existência a fim de provocar a modificação desta. Isso não significa que saúde seja um conceito vazio (2009a, p. 29).

A norma não é uma ordem prescritiva, desprovida de uma individualidade biológica, pois é o vivente que instituirá suas próprias normas, sendo normal aquele que institui novas normas. É nesse sentido que Canguilhem sustenta que a doença não consiste em um desvio local, localizado, mensurável. É na experiência individual, na concretude da vida, que a redução da normatividade se apresenta como patológica. 


\section{O SILÊNCIO DOS ÓRGÃOS}

De acordo com Canguilhem, as técnicas de restauração da saúde inscritas nas concepções positivistas da doença colocadas em prática por Comte e Bernard fazem desaparecer a experiência individual da doença, na medida em que a patologia é entendida apenas como uma variação quantitativa do normal. O médico e cirurgião René Leriche (1870-1955) modifica, segundo Canguilhem, essa relação. Uma vez que a técnica médica é suscitada pelo estado patológico, a medicina deve partir das técnicas terapêuticas para o conhecimento fisiológico, e não o contrário (Canguilhem, 2009a, p. 35). Nesse sentido, é por intermédio da clínica, da experiência terapêutica com o doente, que se pode conhecer o indivíduo normal.

Canguilhem argumenta que ainda que Leriche proceda do estado patológico para conhecer o normal, as técnicas de cura servirão para neutralizar a singularidade do doente (cf. Le Blanc, 2010a, p. 42-3). Assim, se para Leriche "a saúde é a vida no silêncio dos órgãos", esse silêncio não equivale à ausência de doença (Canguilhem, 2009a, p. 35). Isso porque "existem no organismo lesões ou perturbações funcionais que, durante muito tempo, são imperceptíveis para aqueles cuja vida tais perturbações estão colocando em perigo" (2009a, p. 35). Se uma autópsia revelar uma alteração anatômica ou fisiológica, que não era de modo algum sentido pela pessoa viva, então devemos concluir, segundo Leriche, que existia uma doença. A crítica de Canguilhem reside, então, em que, na teoria de Leriche, a experiência vivida do doente é relativizada diante do conhecimento médico da doença; a individualidade é uma alteração insignificante no diagnóstico de uma doença, o que o leva a fazer afirmações como a seguinte: "se quisermos compreender a doença, é necessário desumanizá-la" (Leriche apud Canguilhem, 2009a, p. 35).

Já deve estar claro os motivos que levaram Canguilhem a recusar uma clínica que situa as doenças em lugares cada vez mais específicos do organismo, ao invés de considerar a totalidade orgânica do processo de adoecimento. Ao invés de desumanizar as doenças, Canguilhem busca o caminho inverso, insistindo no papel da clínica para identificar, a partir da percepção do doente, a distinção entre o normal e o patológico. Pois, afirma o autor, "sempre se admitiu, e atualmente é uma realidade incontestável, que a medicina existe porque há homens que se sentem doentes, e não porque existem médicos que os informam de suas doenças" (2009a, p. 36).

No entanto, Canguilhem não propõe que o médico se oriente exclusivamente pelas percepções do paciente, abrindo mão dos diagnósticos oferecidos pelos exames laboratoriais, mas propõe apenas que justamente a singularidade e os sintomas do paciente sejam levados em conta (cf. 2002, p. 38-9). O acompanhamento clínico de Joanda, feito há mais de duas décadas na "Casa de Chagas", parecia levar em conta as duas dimensões, embora, nos exames diagnósticos, sempre haja a referência a uma norma ideal.

Além do cansaço que sentia, relacionado à insuficiência cardíaca congestiva, Joanda voltou a ficar "doente" - ou a sentir aquilo que Mol denominou padecimento - pouco depois de começar seu trabalho como voluntária da Associação:

Um pouco depois que recebi o crachá de voluntária pra poder almoçar, aí fiquei doente. Tive um problema no intestino. Me internei. Eu ia fazer a colostomia. Aí fiz exame, muito exame, muito exame: deu megacólon. Mas também, graças a Deus, não fiz essa cirurgia, que é pra usar a bolsinha; não precisou. Mas também até hoje, minha filha, minhas tripinhas lá dentro é tudo oco. Porque passa tempo, sabe o que é aquele vazio lá 
dentro, e aí estica, estica, estica e não sai nada? É muito ruim. E eu também tenho o problema do esôfago, que o esôfago também é ruim. Vou fazer um exemplo. Eu vou lá na sua casa, a senhora me leva lá. Aquela beleza, aquela fartura na sua mesa. Aí o olho cresce. E se meu olho crescer, vou passar mal. Eu como, aquela quantia boa, aí depois, quando eu pensar que não, eu tô passando mal e a comida fica voltando, e volta tudo. Eu tenho que saber comer pouquinho. E é difícil engolir, também.

Eram as manifestações das formas digestivas crônicas da doença de Chagas, que irrompiam o silêncio dos órgãos de Joanda. Se podemos considerar, juntamente com Canguilhem, que não são as alterações anatomofisiológicas que determinam a doença, mas a percepção do indivíduo que sente uma mudança qualitativa em relação a um estado anterior, o que dizer da angústia diante da possibilidade de descobrir patologias que não são sentidas? Joanda evitava realizar alguns dos exames solicitados movida por essa angústia, mas sempre pensando em seu próprio organismo de maneira um pouco fragmentada, enquanto órgãos doentes:

Aí pronto, é sempre eu nessa questão, né? Cuidando às mil maravilhas do coração. O intestino que é também portador da doença, parece que ele nem existe. Aí parece que volta àquela tecla: que eu era doente e não ligava. Aí fica ruim, não fica, não, pra mim? Por causa de um exame? Eu também tô até devendo, que eu tenho de fazer o esofalograma. Faltou um liquidinho que eu tenho que tomar. Aí não fui mais. Tá vendo? Brinco ou não brinco? E sabendo. E consciente de como é tudinho, e fico eu nessa negligência, por causa de um exame. E muitas pessoas como eu, tem, viu? Parece que se eu for fazer o exame, aí eu descubro coisa pior, é melhor deixar tudo assim, e ficar, e cuidar daquela pessoa que precisa como se eu nunca fosse ficar doente. Se você chega lá no hospital, tem tanta gente pior do que eu, aí quando eu chego em casa, e olho um pouquinho, que chegam as coisas, os sintomas, que são horríveis, aí eu sei que não é brincadeira, não.

Nesse sentido, há uma expectativa de que todas as pessoas infectadas pelo T. cruzi evoluam para uma das formas crônicas da doença e, muitas vezes, elas são vistas como se já estivessem doentes. Decorre disso uma concepção da doença como incurável enquanto irreversibilidade a um estado anterior. Afinal, os dados fisiológicos observáveis após a doença são, em geral, distantes das normas de vida anteriores e, se a cura for assim compreendida, não há volta na tripanossomíase americana. Todavia, se considerarmos o sentido que Canguilhem atribui à cura, de "reconquista de um estado de estabilidade das normas fisiológicas", estando "mais próxima da doença ou da saúde na medida em que essa estabilidade estiver mais ou menos aberta a eventuais modificações” (2009a, p. 92), então a doença de Chagas implica na criação de novas normas de vida e revelando a plasticidade de sua normatividade.

\section{CONSIDERAÇÕES FINAIS: INCURÁVEL}

Para Canguilhem, a definição de saúde não pode passar por uma norma supra individual, obtida por meio de uma média estatística, para determinar se um ser é ou não doente. Não existe, então, uma equivalência entre a normalidade e a saúde, já que o patológico é uma forma de normalidade. Inspirado pela teoria das relações do vivente com o seu meio, de Kurt Goldstein (1878-1965), psiquiatra e neurologista alemão, Canguilhem afirma que a cura é um novo estado de saúde, em que 
a nova saúde não é a mesma que a antiga (...). Curar, apesar dos déficits, sempre é acompanhado de perdas essenciais para o organismo e, ao mesmo tempo, ao reaparecimento de uma ordem. A isso corresponde uma nova norma individual (Goldstein apud Canguilhem, 2009a, p. 76).

Nesse sentido, Canguilhem afirma que o papel do médico consiste em não considerar a saúde enquanto uma "constante de satisfação" (2002, p. 99). Afinal, ainda que crie novas normas, a vida do indivíduo sempre implicará na redução de sua normatividade. O próprio processo de envelhecimento é prova disso. Consistindo na redução progressiva das margens de tolerância às infidelidades do meio, tais modificações poderiam ser consideradas como deficiências para um mesmo indivíduo considerado sucessivamente, embora representem uma normatividade cronológica (cf. Canguilhem, 2009a, p. 130).

De maneira análoga, quando acometido por uma doença crônica, o indivíduo sempre guarda um passado em relação ao qual sua normatividade sofreu um decréscimo. Assim, Canguilhem dirá que o papel do médico na cura consiste em "instruir o doente sobre sua responsabilidade indelegável em sua conquista de um novo estado de equilíbrio com as solicitações do ambiente" (2002, p. 98).

No caso dos indivíduos, essa cura não envolve apenas as solicitações do meio orgânico, mas também do meio social. Isso porque o meio social é constituído e orientado pelo indivíduo, que prefere certas normas a outras. Inventando e recriando o meio na medida em que se adapta a ele, a normatividade social, analogamente à biológica, é entendida por Canguilhem à luz da afirmação de valores, preferindo e excluindo, em suas ações, as normas sociais existentes. Assim, "só há o sujeito porque há, simultaneamente, sujeição a normas sedimentadas e subjetivação dessas mesmas normas. O sujeito é um efeito das normas, mas é um efeito original: ele é um efeito que efetua a si próprio" (Le Blanc, 2010a, p. 91). Sendo a capacidade de engendrar e instituir novas normas aquilo que define a normatividade, a criação de normas é também um ato de subjetivação. E a condição para a produção de novas possibilidades é, para Canguilhem, a errância, que desvenda uma capacidade inventiva frente a situações mutáveis e contingentes. De acordo com Safatle,

a contingência é exatamente aquilo que não poderia ser outro, pois é o que não pode ser intercambiável. A partir do momento em que ela ocorre, o organismo transforma tal acontecimento em motor para a modificação de seu padrão global de regulação, ele abandona as normas, a vida entra em transbordamento em relação às normas anteriores, reorientando sua história ao explorar possíveis que estavam até então em estado de latência. (...)

Por isso, podemos dizer que a contingência leva-nos a uma compreensão mais determinada da processualidade. Por ter propriedades processuais, ela pode colocar-se como fundamento para as transformações do organismo ou, se quisermos, ela se coloca como fundamento para um organismo cuja identidade é definida exatamente pela sua capacidade de entrar em errância, pela sua "capacidade transitiva" de não se deixar pensar sob a forma da identidade (2015, p. 361-2).

A errância é, portanto, onde a normatividade biológica e a normatividade social se aproximam, já que uma adaptação estrita, que impõe uma "especialização excessiva" (Canguilhem, 2009 , p. 55), impede as mudanças frente às infidelidades do meio. Nesse sentido, se a doença de Chagas trouxe a Joanda uma anormalidade no sentido preciso de uma normalidade restrita, criando um novo arranjo orgânico, arriscaria dizer que ela encontrou, no interior das normas

PRACS: Revista Eletrônica de Humanidades do Curso de Ciências Sociais da UNIFAP https://periodicos.unifap.br/index.php/pracs ISSN 1984-4352 Macapá, v. 12, n. 1, p. 153-173, jan./jun. 2019 
sociais, uma normatividade social por meio de sua nova subjetividade doente.

Não tendo frequentado a escola até os seus 25 anos e sem um emprego formal, foi paradoxalmente através da porta do hospital - onde obteve o diagnóstico que engendrou tantas exclusões em sua vida - que Joanda encontrou sua inclusão social. Conforme Joanda foi se envolvendo na Associação, encontrou um campo de ação para ajudar outras pessoas que frequentavam o Ambulatório. Algumas dificuldades surgiram, àquela época, em seu trabalho como voluntária, pois ela era analfabeta. Essa dificuldade inicial foi, na verdade, o caminho por meio do qual Joanda pôde encontrar um reposicionamento subjetivo face às condições impostas pelo meio socioeconômico. Naquele período, ela começou a frequentar a escola, como relata:

Minha história de estudar foi porque eu tinha que pegar os nomes dos pacientes pra ajudar melhor lá na recepção. Aí cheguei em casa e disse a dona Nair, que é a vó das meninas: "eu vou estudar pra trabalhar no hospital, pra eu também ser enfermeira.” Não é que eu peguei no lápis e fui na primeira série, segunda série, terceira série, quarta série. Sabe o que é, né, o que a gente chama de supletivo? Aí fui fazer o supletivo, e não é que eu fiquei estudiosa? Na minha formatura foi uma festa. Ganhei roupa da formatura, sapato, tudinho direitinho. Só não consegui entrar na enfermagem porque o dinheirinho não dava. Mas a senhora pode perguntar: "Joanda, como é que se monitora um paciente?” Eu sei. "Como é que se faz um eletro?” Também sei.

Além disso, a partir do diagnóstico da doença, ${ }^{12}$ ela passou a receber o Benefício de Prestação Continuada de Assistência Social do Instituto Nacional do Seguro Social (INSS). Ainda que Joanda não tenha contribuído com o seguro social, seu diagnóstico permitiu que ela recebesse o benefício da aposentadoria por invalidez pelo fato de ter-se enquadrado como produtora rural. ${ }^{13}$ Com o dinheiro a que tem direito por meio do INSS, Joanda consegue, apesar das dificuldades financeiras, garantir seu sustento e de seu marido, desempregado há mais de um ano.

Assim, a despeito de ter encontrado dificuldades em diferentes níveis, Joanda não foi reduzida às condições socioeconômicas que se lhe apresentaram. Nesse sentido, é notável a irredutibilidade do valor subjetivo diante das múltiplas formas de alienação produzidas pelos meios de vida humana, de que fala Canguilhem (cf. Le Blanc, 2010b, p. 250). Resistindo à dissolução biológica e social, ela encontrou a plasticidade de sua normatividade, produzindo novas possibilidades diante das tensões e da violência que persistem durante toda a história de Joanda. E, na encruzilhada de contradições da doença de Chagas, Joanda encontrou brechas nas instituições de poder (o hospital, o Estado, a família) para expressar seus valores individuais, encontrando significado para a sua experiência.

\footnotetext{
$12 \mathrm{O}$ mero diagnóstico da infecção pelo T. crų̧i não é suficiente para ter acesso ao benefício da Previdência Social. Para tal, é necessário apresentar um eletrocardiograma que indique arritmias ou insuficiência cardíaca e uma radiografia do tórax à perícia médica da Previdência Social, que poderá considerar uma pessoa incapacitada para "exercer suas atividades ou outro tipo de serviço que lhes garanta o sustento” (Ministério da Previdência Social, 2015; cf. Luquetti \& Porto, 1997; Guariento et al., 1999).

${ }^{13}$ No caso de Joanda, o recebimento do seguro social foi possível pelo fato de que, de acordo com o regimento do INSS, "o segurado especial (trabalhador rural) terá direito a um salário mínimo, se não contribuiu facultativamente" (Ministério da Previdência Social, 2015).
} 


\section{REFERÊNCIAS}

ALVES, P. \& RABELO, M. (Org.). Antropologia da saúde: traçando identidade e explorando fronteiras. Rio de Janeiro: Fiocruz / Relume Dumará, 1998.

BENCHIMOL, J. Dos micróbios aos mosquitos: febre amarela e a revolução pasteuriana no Brasil. Rio de Janeiro: Fiocruz / UFRJ, 1999.

CANGUILHEM, G. Écrits sur la médecine. Paris: Seuil, 2002.

O normal e o patológico. Rio de Janeiro: Forense, 2009a.

La connaissance de la vie. Paris: Vrin, 2009b.

CHAGAS, C. Nova entidade mórbida do homem. Brazil Médico, v. 24, n. 43-45, p. 423-428, 433-437, 443-447, 1910.

Nova tripanozomiaze humana. Estudos sobre a morfolojia e o ciclo evolutivo do Schizotrypanum cruzi $n$. gen., $n$. sp., ajente etiolojico de nova entidade morbida do homem. Memórias do Instituto Oswaldo Cruz, v. 1, p. 159-218, 1909. In: CARVALHEIRO, J.; AZEVEDO, N.; ARAÚJO-JORGE, T. et al. (Org.). Clássicos em doença de Chagas: história e perspectivas no centenário da descoberta. Rio de Janeiro: Fiocruz, 2009. p. 51-122.

COUTINHO, M. Ninety years of Chagas disease: a success story at the periphery. Social studies of science, v. 29, n. 4, p. 519-49, 1999.

DELAPORTE, F. A doença de Chagas: história de uma calamidade continental. Trad. de Carmen Pereira \& Leonora de Assis. Ribeirão Preto: Holos, 2003.

FOUCAULT, M. O nascimento da clínica. Rio de Janeiro: Forense, 2006.

FRANÇA, T. C.; SANTOS, M. G. \& FIGUEROA-VILLAR, J. D. Malária: aspectos históricos e quimioterapia. Química Nova, v. 31, n. 5, p. 1271-1278, 2008.

GUARIENTO, M.; CAMILO, M.; CAMARGO, A. Working conditions of Chagas' disease patients in a large Brazilian city. Cadernos de Saúde Pública, v. 15, n. 2, p. 381-6, 1999.

KROPF. S. Doença de Chagas, doença do Brasil: ciência, saúde e nação, 1909-1962. Rio de Janeiro: Fiocruz, 2009.

LE BLANC, G. Canguilhem et les normes. Paris: PUF, 2010a.

Canguilhem et la vie humaine. Paris : PUF : 2010b.

LUQUETTI, A. \& PORTO, C. Aspectos médico-trabalhistas da doença de Chagas. In: DIAS, J. \& COURA, J. (Org.). Clínica e terapêuica da doença de Chagas: uma abordagem para o clínico geral. Rio de Janeiro: Fiocruz, 1997. p. 353-64.

LYONS. M. The colonial disease: a social history of sleeping sickness in northern Zaire, 1990-1940. Cambridge / Nova Iorque/ Port Chester / Melbourne / Sidney: Cambridge University Press, 2002.

MARQUES, R. J. Alguns aspectos da doença de Chagas em Pernambuco. Recife: 1955. Tese (concurso para provimento do cargo de Professor Catedrático da Cadeira de Clínica de Doenças Tropicais e Infectuosas). Faculdade de Medicina, Universidade do Recife, 1955.

MINISTÉRIO DA PREVIDÊNCIA SOCIAL. Aposentadoria por invalidez. Brasília, 2015. Disponível em: < http://agencia.previdencia. gov.br/e-aps/servico/381>. Acesso em 17 mar. 17.

MOL, A. The body multiple. Ontology in medical practice. Durham / Londres: Duke University Press, 2002.

OMS. Working to overcome the global impact of neglected tropical diseases. First WHO report on neglected tropical diseases. Genebra, 2010. 
PRADO JR., C. Formação do Brasil contemporâneo: colônia. São Paulo: Companhia das Letras, 2011.

RIBEIRO, D. O povo brasileiro: a formação e o sentido do Brasil. São Paulo: Companhia das Letras, 1995.

ROMAÑA, C. Acerca de un síntoma inicial de valor para o diagnóstico de forma aguda de la enfermedad de Chagas. La conjutivitis esquizotripanósica unilateral : hipótesis sobre la puerta de entrada conjuntival de la enfermedad. In: CARVALHEIRO, J. et al. (Org.). Clássicos em doença de Chagas: história e perspectivas no centenário da descoberta. Rio de Janeiro: Fiocruz, 2009 [1935]. p. 205-220.

ROUDINESCO, E. Filósofos na tormenta: Canguilhem, Sartre, Foucault, Althusser, Deleuze e Derrida. Rio de Janeiro: Jorge Zahar, 2007.

SAFATLE, V. Uma certa latitude: Georges Canguilhem, biopolítica e vida como errância. Scientiae Studia, v. 13, n. 2, p. 335-67, 2015.

TORTORA, G.; FUNKE, B. \& CASE, C. Microbiologia. Porto Alegre: Artmed, 2012. VIOLI, M. P. Les origines du genre gramatical. Langages, v. 21, n. 85, p. 15-34, 1987. ZABALA, J. La enfermedad de Chagas en la Argentina: investigación científica, problemas sociales y políticas sanitarias. Bernal: Universidad Nacional de Quilmes, 2010. 